\title{
Genetic Basis and Monitoring of Resistance of Botryotinia fuckeliana to Anilinopyrimidines
}

\author{
Urs W. Hilber and Maja Hilber-Bodmer, Department of Plant Pathology, Swiss Federal Research Station, CH- \\ 8820 Waedenswil, Switzerland
}

\begin{abstract}
Hilber, U. W., and Hilber-Bodmer, M. 1998. Genetic basis and monitoring of resistance of Botryotinia fuckeliana to anilinopyrimidines. Plant Dis. 82:496-500.

The anilinopyrimidines constitute a new class of mainly protective, broad-spectrum fungicides with a high activity against Botryotinia fuckeliana, the causal agent of gray mold on a wide range of host plants. The present study was initiated to investigate the genetic basis of resistance to anilinopyrimidines in $B$. fuckeliana and to assess the frequency of resistant isolates in vineyards in Switzerland exposed to experimental applications of anilinopyrimidines. In mating experiments, two sensitive reference isolates were crossed with three anilinopyrimidine-resistant field isolates. The analysis of 72 sexual progeny from six apothecia demonstrated that resistance to the anilinopyrimidine fungicide cyprodinil segregated in a 1:1 ratio and is therefore monogenic. The same segregation ratio was found for resistance to the dicarboximide fungicide vinclozolin. Resistance to cyprodinil segregated independently from resistance to vinclozolin. From 1993 to 1995, isolates of B. fuckeliana were collected in Switzerland from five vineyards that differed in their anilinopyrimidine spray history. Of a total of 303 isolates tested in vitro, three anilinopyrimidine-resistant isolates were detected in two vineyards where the cumulative number of treatments was between two and nine. The results of the study are discussed with respect to the implementation of an antiresistance strategy in Switzerland.
\end{abstract}

The anilinopyrimidines constitute a new class of mainly protective fungicides with a broad spectrum of activity against different pathogens, including Botryotinia fuckeliana (de Bary) Whetzel (Botrytis cinerea), the causal agent of gray mold on a wide range of host plants $(8,10,19,22)$. The representatives cyprodinil (CGA 219417; $N$-(4-cyclopropyl-6-methylpyrimidin-2-yl) aniline), mepanipyrim (KIF 3535; $N$-(4methyl-6-prop-1-ynylpyrimidin-2yl)aniline), and pyrimethanil ( $N$-(4,6-dimethylpyrimidin-2-yl)aniline) have been introduced in European countries recently (18). In Switzerland, all three active ingredients have been registered since 1995 . The mode of action of anilinopyrimidines differs from that of other classes of fungicides $(8,18)$. Specific interference with the biosynthesis of methionine $(8,20)$ and the inhibition of the secretion of hydrolytic enzymes have been demonstrated $(8,21)$.

In vitro, the inhibition of mycelial growth on media amended with anilinopyrimidines depends on the complexity of the media and is greatly reduced in "rich" growth conditions $(1,12,18)$. Reliable test methods, baseline sensitivity data, and

Corresponding author: U. W. Hilber

E-mail: urs.hilber@mbox.faw.admin.ch

Accepted for publication 17 January 1998.

Publication no. D-1998-0304-01R

(C) 1998 The American Phytopathological Society evidence for cross resistance of all three anilinopyrimidine fungicides in B. fuckeliana were published recently $(1,12,13)$.

In 1994 in a special trial site of Ciba in Ruedlingen, Switzerland (7), intensive use of anilinopyrimidines over a period of 8 years resulted in an increased frequency of resistant isolates and led to a failure of disease control $(7,12)$. The sensitivity results from these plots suggested that a qualitative, disruptive selection has occurred, which is typical for one-gene mutation (12).

The present investigation was initiated to study the genetic basis of resistance to anilinopyrimidines and to assess the resistance frequency in vineyards in Switzerland that had experimentally received different numbers of anilinopyrimidine treatments. Segregation of resistance to anilinopyrimidines and resistance to dicarboximides were investigated. Several populations of $B$. fuckeliana were monitored, and crosses of anilinopyrimidinesensitive and -resistant field isolates from the special Ruedlingen area were analyzed. The genetics of anilinopyrimidine resistance is a crucial element in the assessment of inherited resistance risks $(11,14,15)$ and influences the design and success of antiresistance strategies.

\section{MATERIALS AND METHODS}

Chemicals. Active ingredients (technical grade) of the anilinopyrimidine and the dicarboximide fungicides cyprodinil and vinclozolin were provided by the manu- facturers (Ciba, Basel, Switzerland and BASF, Ludwigshafen, Germany). All other chemicals used were purchased from E. Merck, Buchs, Switzerland.

Media. The following three media were used: (i) cultures of $B$. fuckeliana were maintained on pea agar (160 g of green peas, $5 \mathrm{~g}$ of saccharose, $15 \mathrm{~g}$ of agar, and 1 liter of distilled water); (ii) the sensitivity of $B$. fuckeliana to dicarboximides was tested on a complex medium (malt-agar: $15 \mathrm{~g}$ of malt extract, $15 \mathrm{~g}$ of agar, and 1 liter of distilled water) amended with vinclozolin; and (iii) the sensitivity to anilinopyrimidines was tested using a synthetic medium (asp-agar) supplemented with cyprodinil. This medium was described by Hammer et al. (9) and was later modified by Hilber and Schüepp $(12,13)$. Cyprodinil and vinclozolin were dissolved in acetone and ethanol, respectively, before mixing with the agar that was cooled to 45 to $50^{\circ} \mathrm{C}$. In all cases (including control plates), the final acetone or ethanol concentration was $1 \%$ (vol/vol). Agar $(20 \mathrm{ml})$ was poured into $9-\mathrm{cm}$ plastic petri dishes.

Sexual crosses and genetic analysis. Five isolates of $B$. fuckeliana were used in sexual crosses. Isolate $\mathrm{CH} 9.83$ was collected from diseased grapes in a Swiss vineyard in 1983. It was provided by Ciba as an anilinopyrimidine-sensitive reference isolate. Isolate F31.5 is a reference isolate from the culture collection of the Swiss Federal Research Station, Waedenswil. It is a sexual progeny from a cross of two $B$. fuckeliana isolates collected from strawberries in 1993. Isolate F26.91 was collected in a monitoring program in 1991 in a vineyard in France and was provided by Ciba. Isolates Z103.16 and Z203.21 were collected from diseased grapes in 1995 in an experimental plot from Ciba. This plot was located in a vineyard in Ruedlingen where a control failure of cyprodinil was encountered in $1994(7,12)$.

Isolates $\mathrm{CH} 9.83$ and $\mathrm{F} 31.5$ were crossed with isolates Z103.16, Z203.21, and F26.91, respectively. In the cross CH9.83 $\times$ $\mathrm{Z} 103.16$, isolate $\mathrm{CH} 9.83$ was used as sclerotial partner; whereas in the cross Z203.21 $\times \mathrm{CH} 9.83$, the same isolate was used as spermatizing partner. In the cross F26.91 $\times$ F31.5, isolate F26.91 was used as the sclerotia partner. The sensitivity of all five isolates was assessed prior to their use for sexual crosses.

Matings were carried out as described by Faretra et al. (4). Random asci were 
dissected using a micromanipulator (Maerzhaeuser DC-3K) as described elsewhere (23). Ascospores of B. fuckeliana frequently change their order during the final mitotic division $(6,25)$. Therefore, octads were not collected in an ordered way. Sets of eight ascospores from single asci were separated on malt agar dishes, transferred to pea-agar slants, and subjected to mycelial growth tests on malt agar and asp-agar amended with vinclozolin or cyprodinil, respectively.

Sampling for resistance monitoring. Grape berries diseased with $B$. fuckeliana were collected in vineyards in Walenstadt, Staefa, Waedenswil, Richterswil, and Hoengg (Switzerland), where anilinopyrimidines were applied experimentally prior to their Swiss registration in 1995. The highest cumulated number of anilinopyrimidine treatments in these vineyards was nine. None of the vineyards received more than two anilinopyrimidine treatments per year. In 1993, isolates were collected from the vineyards in Walenstadt and Staefa, in 1994, from Walenstadt, and in 1995, from all five vineyards. The anilinopyrimidine history of the vineyards is summarized in Table 1. Anilinopyrimidine fungicides were applied in a mixture with the phenylpyrrole fungicide fludioxonil; however, in Staefa in 1989 and in Richterswil in 1994, anilinopyrimidines were applied once and twice, respectively, without the mixing partner.

Shortly before harvest, single diseased grape berries were collected randomly from treated plots (except in 1993, when samples from Walenstadt came from an untreated plot [=baseline]). Isolation and propagation of $B$. fuckeliana was done as described in detail elsewhere $(12,15)$.

Sensitivity test. The sensitivity of ascospore progeny and of field isolates was determined as follows. Agar disks $(8 \mathrm{~mm}$ diameter) were cut from malt agar and aspagar, respectively. The agar disks were inoculated with $20 \mu \mathrm{l}$ of a conidial suspension $\left(10^{5}\right.$ conidia $\left.\mathrm{ml}^{-1}\right)$ and incubated for $17 \mathrm{~h}$ at $20^{\circ} \mathrm{C}$ in the dark. These disks were then placed upside-down onto plates containing either malt agar or asp-agar without vinclozolin and cyprodinil, or amended with cyprodinil and vinclozolin at various concentrations. For monitoring tests, one discriminatory dose was chosen for each fungicide: $0.03 \mu \mathrm{g} \mathrm{ml}^{-1}$ was selected for cyprodinil and $1 \mu \mathrm{g} \mathrm{ml}^{-1}$ for vinclozolin, as described elsewhere $(11,12)$. Isolates were considered resistant when, compared with the control growth on agar not supplemented with fungicides, their relative growth on the fungicide-amended agar was $>50 \%$, that is, their $\mathrm{ED}_{50}$ was $>0.03 \mu \mathrm{g} \mathrm{ml}^{-1}$ for cyprodinil and $>1 \mu \mathrm{g} \mathrm{ml}^{-1}$ for vinclozolin, respectively. Ascospore progeny were tested with a series of doses of cyprodinil: $0,0.001,0.01,0.1$, and 1 to 10 $\mu \mathrm{g} \mathrm{ml}^{-1}$, and of vinclozolin: $0.1,1$, and 10 to $100 \mu \mathrm{g} \mathrm{ml}^{-1}$. Anilinopyrimidine-resistant isolates detected in the resistance monitoring were retested.

All cultures were incubated for 3 days at $20^{\circ} \mathrm{C}$. The mean colony diameter minus the diameter of the inoculation disk was measured and expressed as the percentage of the mean colony diameter of the untreated control. Each test was performed three times.

Data analysis. Data from sexual crosses were statistically analyzed for the segregation of sensitive and resistant phenotypes and for the independent segregation of the fungicide resistance markers by means of chi-square test.

Categorical fungicide sensitivity data obtained for the populations of B. fuckeliana from five vineyards were compared with baseline data by fitting log-linear models supplied by JMP (SAS Institute, Cary, NC) according to Köller et al. (17). Isolates were grouped into the categories cyprodinil sensitive $\left(\mathrm{ED}_{50}<0.03 \mu \mathrm{g} \mathrm{ml}^{-1}\right)$ and resistant $\left(\mathrm{ED}_{50}>0.03 \mu \mathrm{g} \mathrm{ml}^{-1}\right)$. Baseline data were obtained from Walenstadt (1993) and were pooled with data published previously (12).

\section{RESULTS}

Sexual crosses and genetic analysis. The sensitivity to cyprodinil was assessed for isolates $\mathrm{CH} 9.83$, F31.5, Z103.16, Z203.21, and F26.91 before they were used in sexual crosses. The $\mathrm{ED}_{50}$ values of the reference isolates $\mathrm{CH} 9.83$ and $\mathrm{F} 31.5$ were $<0.03 \mu \mathrm{g} \mathrm{ml}{ }^{-1}$.

According to Köller's definition of field resistance (16), which is based on significant frequency increase of resistant phenotypes at sites with control failure, isolates with $\mathrm{ED}_{50}>0.03 \mu \mathrm{g} \mathrm{ml} \mathrm{m}^{-1}$ were considered to be resistant (12). Isolates Z103.16 and Z203.21, both collected in Ruedlingen from a vineyard with a documented case of anilinopyrimidine resistance (7), and isolate F26.91 showed ED 50 values of 10,2 , and $1 \mu \mathrm{g} \mathrm{ml}^{-1}$, respectively, and were therefore classified as being resistant to cyprodinil (Table 2). Previous assessment of the sensitivity to dicarboximides revealed that isolates F26.91 and Z103.16 were also resistant to vinclozolin; whereas isolates $\mathrm{CH} 9.83, \mathrm{Z203.21}$, and F31.5 were sensitive (data not shown).

A total of 72 sexual progeny from three crosses between five isolates were analyzed to elucidate the genetic basis of resistance to cyprodinil. In sexual crosses of Z203.21 $\times$ CH9.83, resistance to cyprodinil segregated in a 1:1 ratio in all four asci analyzed. This segregation ratio was confirmed by analysis of crosses $\mathrm{CH} 9.83 \times$ Z103.16 and F26.91 $\times$ F31.5. Of totals of 16 and 24 progeny tested from these crosses, 8 and 12 progeny, respectively, were resistant to cyprodinil (Table 3). The segregation of resistant and sensitive progeny in a 1:1 ratio in all crosses demon-

Table 1. Monitoring of resistance of Botryotinia fuckeliana to cyprodinil in Swiss vineyards from 1993 to 1995

\begin{tabular}{|c|c|c|c|c|c|c|c|}
\hline \multirow[b]{2}{*}{ Year } & \multirow{2}{*}{$\begin{array}{l}\text { Monitoring } \\
\text { sites }\end{array}$} & \multirow{2}{*}{$\begin{array}{c}\text { AP- } \\
\text { treatments }^{\mathrm{a}}\end{array}$} & \multirow[b]{2}{*}{$n^{b}$} & \multicolumn{2}{|c|}{$\begin{array}{c}\text { Cyprodinil } \\
\text { ED }_{50}\left(\mu \mathrm{g} \mathrm{ml}^{-1}\right)\end{array}$} & \multirow[b]{2}{*}{$\mathbf{F R}^{\mathbf{c}}$} & \multirow[b]{2}{*}{$P^{d}$} \\
\hline & & & & $<0.03$ & $>0.03$ & & \\
\hline 1993 & Baseline $^{\mathrm{e}}$ & 0 & 100 & 100 & 0 & 0 & \\
\hline 1993 & $\begin{array}{l}\text { Walenstadt } \\
\text { (=baseline) }\end{array}$ & 0 & 40 & 40 & 0 & 0 & \\
\hline 1993 & Staefa & 9 & 40 & 39 & 1 & 2.5 & 0.08 \\
\hline 1994 & Walenstadt & 2 & 40 & 40 & 0 & 0 & 1 \\
\hline 1995 & Walenstadt & 4 & 40 & 40 & 0 & 0 & 1 \\
\hline 1995 & Staefa & $2^{f}$ & 39 & 38 & 1 & 2.5 & 0.08 \\
\hline 1995 & Hoengg & 4 & 40 & 40 & 0 & 0 & 1 \\
\hline 1995 & Richterswil & 8 & 20 & 19 & 1 & 5 & 0.04 \\
\hline 1995 & Waedenswil & $2^{g}$ & 44 & 44 & 0 & 0 & 1 \\
\hline
\end{tabular}

${ }^{a}$ Number of anilinopyrimidine treatments.

${ }^{\mathrm{b}}$ Number of isolates tested.

${ }^{c}$ Frequency of anilinopyrimidine-resistant isolates.

${ }^{\mathrm{d}}$ Comparison of baseline data with populations specified (log-linear models). Baseline data from Hilber and Schüepp (12) were pooled with data obtained in Walenstadt in 1993.

e Baseline data from Hilber and Schüepp (12).

${ }^{f}$ A neighboring plot of the one monitored in 1993 was used because the vineyard was replanted and changed into a terraced plantation in 1994.

$\mathrm{g}$ Adjacent to the trial plot, anilinopyrimidines were sprayed twice per year in the previous 2 years.

Table 2. Isolates of Botryotinia fuckeliana used for sexual crosses

\begin{tabular}{lllc}
\hline Isolate & Year & \multicolumn{1}{c}{ Origin } & $\begin{array}{c}\text { Cyprodinil } \\
\mathbf{E D}_{\mathbf{5 0}}\left(\boldsymbol{\mu \mathbf { ~ m l } ^ { - 1 }}\right)\end{array}$ \\
\hline CH983 & 1983 & Switzerland (ref. isolate Ciba) & 0.003 \\
F31.5 & 1993 & Switzerland (ref. isolate FAW & 0.003 \\
F26.91 & 1991 & France & 1 \\
Z203.21 & 1995 & Switzerland (Ruedlingen) & 2 \\
Z103.16 & 1995 & Switzerland (Ruedlingen) & 10 \\
\hline
\end{tabular}

${ }^{a}$ Swiss Federal Research Station Waedenswil. 
strates that cyprodinil resistance is monogenic (Table 3).

A 1:1 segregation ratio was also found when the sexual progeny were analyzed with respect to segregation of resistance to the dicarboximide fungicide vinclozolin (Table 3), confirming results published elsewhere $(5,11,15)$.

Progeny of crosses CH9.83 $\times$ Z103.16 and F26.91 $\times$ F31.5 showed an independent segregation of the two resistance markers (Table 3). While both asci analyzed from the cross $\mathrm{CH} 9.83 \times \mathrm{Z} 103.16$ were tetratypes, in cross F26.91 × F31.5, one nonparental ditype and two tetratypes, respectively, were found. The independent segregation of resistance to vinclozolin and to cyprodinil indicates that these resistances are encoded by different genes. None of the isolates produced apothecia when selfed. Crosses between the cyprodinil resistant parental strains (Z203.21, Z103.16, and F26.91) were not successful; therefore, allelism could not be tested.

Resistance monitoring. From 1993 to 1995 , the frequency of anilinopyrimidineresistant isolates ranged from 0 to $5 \%$ with sample sizes of 20 to 44 isolates. Of the total of 303 tested isolates of B. fuckeliana, three $(1 \%)$ were resistant to anilinopyrimidine fungicides (Table 1). In 1993, one cyprodinil-resistant isolate (St93.2) with $\mathrm{ED}_{50}>0.1 \mu \mathrm{g} \mathrm{ml}^{-1}$ was found in the vineyard at Staefa. In 1994, no cyprodinilresistant isolates were found in the vineyard in Walenstadt, where anilinopyrimidines had been applied twice. However, in 1995, one anilinopyrimidine-resistant isolate was detected in each of the vineyards in Staefa (S3.2) and in Richterswil (R20), respectively. The vineyard in Richterswil had received eight anilinopyrimidine treatments. The vineyard monitored in 1993 in Staefa was terraced and re- planted in 1994; therefore, in 1995 samples had to be collected in a neighboring plot that only received two anilinopyrimidine treatments until 1995. $\mathrm{ED}_{50}$ values of the anilinopyrimidine-resistant isolates detected in 1995 were 2 and $8 \mu \mathrm{g}$ of cyprodinil $\mathrm{ml}^{-1}$. Dose-response curves of the anilinopyrimidine-resistant isolates detected in 1993 and 1995 are shown in Figure 1.

Additionally, in 1993, the frequency of dicarboximide-resistant isolates was assessed in the vineyards in Walenstadt and in Staefa, where fungicides of this group had been widely used in the past. The precise history of dicarboximide use is not known. The sensitivity to the standard product vinclozolin was assessed for 40 isolates in each vineyard. As defined pre- viously, isolates were considered to be resistant to vinclozolin if their $\mathrm{ED}_{50}$ values were $>1 \mu \mathrm{g} \mathrm{ml}^{-1}$ (15). The total frequencies of vinclozolin-resistant isolates were 5\% in Staefa and $45 \%$ in Walenstadt, respectively. Different frequencies of cyprodiniland vinclozolin-resistant isolates confirmed the results of the genetic analysis, indicating the lack of cross resistance between dicarboximides and anilinopyrimidines.

\section{DISCUSSION}

B. fuckeliana has developed resistance to different fungicides in the past $(2,3,11,24)$. Therefore, the commercial introduction of new fungicides against gray mold requires careful assessment of the risk of resistance buildup and the develop-

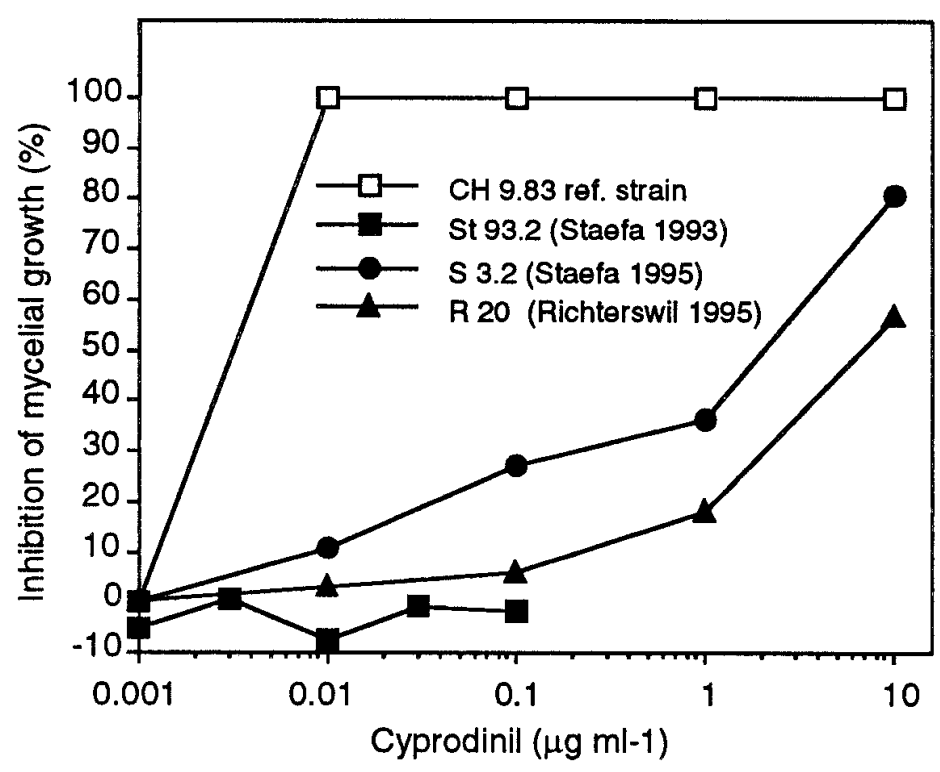

Fig. 1. Percent inhibition of colony growth of Botryotinia fuckeliana field isolates resistant to cyprodinil.

Table 3. Phenotypes and numbers of ascospore progeny of crosses between anilinopyrimidine or dicarboximide resistant field isolates and sensitive isolates of Botryotinia fuckeliana

\begin{tabular}{|c|c|c|c|c|c|c|c|c|}
\hline \multicolumn{2}{|c|}{ Crosses (partner) } & \multirow[b]{2}{*}{ Apothecia } & \multirow[b]{2}{*}{ Asci } & \multicolumn{4}{|c|}{ Phenotypes of progeny } & \multirow[b]{2}{*}{ Chi-square $^{\mathrm{e}}$} \\
\hline Sclerotial & Spermatizing & & & $\mathbf{A}_{\mathrm{s}}^{\mathrm{a} /} / \mathbf{V}_{\mathrm{s}}^{\mathrm{b}}$ & $A_{s} / V_{f r}{ }^{c}$ & $\mathbf{A}_{\mathrm{fr}}^{\mathrm{d}} / \mathbf{V}_{\mathrm{s}}$ & $\mathbf{A}_{\mathrm{fr}} / \mathbf{V}_{\mathrm{fr}}$ & \\
\hline Z203.21 & CH9.83 & 2 & $4^{\mathrm{f}}$ & 4 & 0 & 4 & 0 & \\
\hline \multirow[t]{4}{*}{$\left(\mathrm{A}_{\mathrm{fr}} / \mathrm{V}_{\mathrm{s}}\right)$} & $\left(\mathrm{A}_{\mathrm{s}} / \mathrm{V}_{\mathrm{s}}\right)$ & & & 4 & 0 & 4 & 0 & \\
\hline & & & & 4 & 0 & 4 & 0 & \\
\hline & & & & 4 & 0 & 4 & 0 & \\
\hline & & & Total & 16 & 0 & 16 & 0 & 0 \\
\hline CH9.83 & Z103.16 & 1 & 2 & 2 & 2 & 2 & 2 & \\
\hline \multirow[t]{2}{*}{$\left(\mathrm{A}_{\mathrm{s}} / \mathrm{V}_{\mathrm{s}}\right)$} & $\left(\mathrm{A}_{\mathrm{fr}} / \mathrm{V}_{\mathrm{fr}}\right)$ & & & 2 & 2 & 2 & 2 & \\
\hline & & & Total & 4 & 4 & 4 & 4 & 0 \\
\hline F26.91 & F31.5 & 3 & $3^{\mathrm{g}}$ & 0 & 4 & 4 & 0 & \\
\hline \multirow{3}{*}{$\left(\mathrm{A}_{\mathrm{fr}} / \mathrm{V}_{\mathrm{fr}}\right)$} & $\left(\mathrm{A}_{\mathrm{s}} / \mathrm{V}_{\mathrm{s}}\right)$ & & & 2 & 2 & 2 & 2 & \\
\hline & & & & 2 & 2 & 2 & 2 & \\
\hline & & & Total & 4 & 8 & 8 & 4 & 2.7 \\
\hline
\end{tabular}

${ }^{a}$ Sensitive to anilinopyrimidines; $\mathrm{ED}_{50}$ cyprodinil $<0.03 \mu \mathrm{g} \mathrm{ml}{ }^{-1}$.

${ }^{\mathrm{b}}$ Sensitive to dicarboximides; $\mathrm{ED}_{50}$ vinclozolin $<1 \mu \mathrm{g} \mathrm{ml}{ }^{-1}$.

${ }^{\mathrm{c}}$ Field resistant to dicarboximides; $\mathrm{ED}_{50}$ vinclozolin $>1 \mu \mathrm{g} \mathrm{ml^{-1 }}$

${ }^{\mathrm{d}}$ Field resistant to anilinopyrimidines; $\mathrm{ED}_{50}$ cyprodinil $>0.03 \mu \mathrm{g} \mathrm{ml}^{-1}$

${ }^{\mathrm{e}}$ Chi-square values for segregation at 1:1 ratios of resistant:sensitive phenotypes and recombinant:parental phenotypes, respectively. Chi-square value for $1 \mathrm{df}$ is 3.84 with $P=0.05$.

${ }^{\mathrm{f}}$ Two asci per apothecium.

g One ascus per apothecium. 
ment and implementation of preventive antiresistance strategies. In our previous work, we described a reliable method for in vitro testing of the sensitivity of B. fuckeliana to anilinopyrimidine fungicides $(12,13)$. This test procedure was used to establish a baseline for cyprodinil (12) and to confirm that the loss of efficacy of cyprodinil in an experimental plot of Ciba in Ruedlingen, Switzerland, was due to the selection of a high proportion of anilinopyrimidine-resistant isolates $(7,12)$. In the present study, we investigated the genetic basis of resistance to anilinopyrimidines in B. fuckeliana. Sensitive reference isolates were crossed with anilinopyrimidine-resistant field isolates. Self-compatibility did not occur. None of the isolates produced apothecia when selfed. Tetrad analysis of the successful crosses revealed that resistance to anilinopyrimidines segregated in a 1:1 ratio, indicating monogenic resistance. Resistance to the dicarboximide fungicide vinclozolin also segregated in a 1:1 ratio. However, genetic analysis demonstrated independent segregation of the resistance to anilinopyrimidines and dicarboximides. Although allelism could not be tested because of the lack of successful crosses between cyprodinil-resistant parental strains (Z203.21, Z103.16, and F26.91), our results show evidence for the hypothesis that resistance to anilinopyrimidines and dicarboximides is monogenic and encoded by different genes. This hypothesis is supported by the absence of cross resistance between these two fungicide groups (10).

The frequency of anilinopyrimidine-resistant isolates was determined in five Swiss vineyards in 3 consecutive years. In 1993, one anilinopyrimidine-resistant isolate was detected in the vineyard in Staefa, which had previously received a total of nine anilinopyrimidine treatments. In 1994, this vineyard remained untreated as it was rearranged and terraced. This massive disturbance in pathogen population structure influenced the system in such a way that the selection process did not continue. However, when in 1995 a new neighboring trial plot that had received two anilinopyrimidine treatments was examined, again one cyprodinil-resistant isolate was found. The third anilinopyrimidine-resistant isolate was collected in 1995 from the vineyard in Richterswil that had received eight anilinopyrimidine treatments. In all other vineyards, no isolates with a decreased sensitivity to cyprodinil were detected with the sample size used. In the comparison of isolate counts grouped into the categories sensitive and resistant, the frequency of cyprodinil-resistant isolates from Richterswil in 1995 was significantly different $(P$ $=0.04$ ) from the baseline distribution, demonstrating that the population from Richterswil had shifted. With the sample size used, the frequencies of anilinopyrimidine-resistant isolates in the vine- yard of Staefa were not significantly different $(P=0.08)$ from the baseline. However, data suggested that there is a tendency of the population of Staefa to shift toward reduced sensitivity. In the vineyard of Richterswil, the population shift was not accompanied by a control failure when anilinopyrimidines were applied at commercial field rates (U. W. Hilber, unpublished). Further studies on the population dynamics, persistence, and selection of resistant strains are needed to determine the resistance frequency that must be achieved before control failures as experienced in Ruedlingen, Switzerland, (11) can occur.

In conclusion, B. fuckeliana appears to constitute a high inherent resistance risk to anilinopyrimidines due to the fact that (i) three field-resistant isolates have been detected in two Swiss vineyards in a sample of 99 isolates; (ii) a loss of control due to the occurrence of field resistance was encountered in an experimental plot in Ruedlingen, Switzerland, after prolonged and intensive experimental use of anilinopyrimidines; and (iii) there is evidence that resistance to anilinopyrimidines in $B$. fuckeliana is monogenic, and consequently a selection of the disruptive type could be expected. Therefore, the implementation of sound antiresistance strategies is crucial.

In 1995, all anilinopyrimidines were registered in Switzerland and are in late stages of development worldwide. Due to the knowledge of a high resistance risk of $B$. fuckeliana to anilinopyrimidines, a preventive antiresistance strategy was implemented in Switzerland. The use of anilinopyrimidines as single products for the control of B. fuckeliana has been restricted to one single application per season. Alternatively, if anilinopyrimidines are used in mixture with another active ingredient of high efficacy against B. fuckeliana, e.g., fludioxonil, two applications of the respective mixture are allowed per season.

Anilinopyrimidines provide the unique opportunity to study the influence of different antiresistance strategies, e.g., the use of product mixtures versus alternation, on a typical disruptive selection process. Studies in field trials from 1991 to 1995 have so far indicated that these strategies are effective in maintaining the sensitivity of B. fuckeliana to the anilinopyrimidines (7).

\section{ACKNOWLEDGMENTS}

We thank Karin Langenegger and Yvonne Schaefli for technical assistance. The authors are grateful to Ciba for funding this work.

\section{LITERATURE CITED}

1. Birchmore, R. J., and Forster, B. 1996. FRAC methods for monitoring the sensitivity of $\mathrm{Bo}$ trytis cinerea to anilinopyrimidine fungicides developed by the anilinopyrimidine fungicide resistance action committee of GIFAP. EPPO Bull. 26:181-197.

2. Coley-Smith, J. R., Verhoeff, K., and Jarvis, W. R. 1980. The biology of Botrytis. Academic Press, London.
3. Delp, C. 1988. Fungicide Resistance in North America. American Phytopathological Society, St. Paul, MN.

4. Faretra, F., Antonacci, E., and Pollastro, S. 1988. Improvement of the technique used for obtaining apothecia of Botryotinia fuckeliana (Botrytis cinerea) under controlled conditions. Ann. Microbiol. Enzimol. 38:29-40.

5. Faretra, F., and Pollastro, S. 1991. Genetic basis of resistance to benzimidazole and dicarboximide fungicides in Botryotinia fuckeliana (Botrytis cinerea). Mycol. Res. 95:943951.

6. Faretra, F., and Pollastro, S. 1996. Genetic studies of the phytopathogenic fungus Botryotinia fuckeliana (Botrytis cinerea) by analysis of ordered tetrads. Mycol. Res. 100:620624.

7. Forster, B., and Staub, T. 1996. Basis for use strategies of anilinopyrimidine and phenylpyrrole fungicides against Botrytis cinerea. Crop Prot. 15:529-537.

8. Gasztonyi, M., and Lyr, H. 1995. Miscellaneous fungicides. Pages 389-414 in: Modern Selective Fungicides-Properties, Applications, Mechanisms of Action. H. Lyr, ed. Gustav Fischer Verlag, Jena, Germany.

9. Hammer, P. E., Evensen, K. B., and Janisiewicz, W. J. 1993. Postharvest control of Botrytis cinerea on cut rose flowers with pyrrolnitrin. Plant Dis. 77:283-286.

10. Heye, U. J., Speich, J., Siegle, H., Steinemann, A., Forster, B., Knauf-Beiter, G., Herzog, J., and Hubele, A. 1994. CGA 219417: A novel broad-spectrum fungicide. Crop Prot. 7:541-549.

11. Hilber, U. W. 1992. Comparative studies on genetic variability and fungicide resistance in Botryotinia fuckeliana (de Bary) Whetzel against vinclozolin and the phenylpyrrole CGA 173506. Ph.D. thesis. University of Basel, Switzerland.

12. Hilber, U. W., and Schüepp, H. 1996. A reliable method for testing the sensitivity of Botryotinia fuckeliana to anilinopyrimidines in vitro. Pestic. Sci. 47:241-247.

13. Hilber, U. W., and Schüepp, H. 1996. Mycelial growth test for assessment of anilinopyrimidine sensitivity of grey mould (Botryotinia fuckeliana). EPPO Bull. 26:184-186.

14. Hilber, U. W., Schüepp, H., and Schwinn, F. J. 1994. Resistance risk evaluation of fludioxonil, a new phenylpyrrole fungicide. Pages 397-402 in: Fungicide Resistance, Monograph No. 60. S. Heaney, D. Slawson, D. W. Hollomon, M. Smith, P. E. Russel, and D. W. Perry, eds. Br. Crop Prot. Counc., Farnham, Surrey, UK.

15. Hilber, U. W., Schwinn, F. J., and Schüepp, H. 1995. Comparative resistance patterns of fludioxonil and vinclozolin in Botryotinia fuckeliana. J. Phytopathol. 143:423-428.

16. Köller, W. 1991. Fungicide resistance in plant pathogens. Pages 697-720 in: CRC Handbook of Pest Management in Agriculture. Vol. 2. 2nd ed. D. Pimentel, ed. CRC Press, Boca Raton, FL.

17. Köller, W., Wilcox, W. F., Barnard, J., Jones, A. L., and Braun, P. G. 1997. Detection and quantification of resistance of Venturia inaequalis populations to sterol demethylation inhibitors. Phytopathology 87:184-190.

18. Leroux, P. 1996. Recent developments in the mode of action of fungicides. Pestic. Sci. 47:191-197.

19. Maeno, S., Miura, I., Masuda, K., and Nagata, T. 1990. Mepanipyrim (KIF-3535), a new pyrimidine fungicide. Proc. Br. Crop Prot. Conf. Pests Dis. 2:415-422.

20. Masner, P., Muster, P., and Schmid, J. 1994. Possible methionine biosynthesis inhibition by pyrimidinamine fungicides. Pestic. Sci. 42:163-166. 
21. Miura, J., Kamakura, T., Maeno, S., Hayashi, S., and Yamagushi, J. 1994. Inhibition of enzyme secretion in plant pathogens by mepanipyrim, a novel fungicide. Pestic. Biochem. Physiol. 48:222-228.

22. Neumann, G. L., Winter, E. H., and Pittis, J. E. 1992. Pyrimethanil: A new fungicide. Proc.
Br. Crop Prot. Conf. Pests Dis. 1:395-402.

23. Shermann, F., and Hicks, J. 1991. Micromanipulation and dissection of asci. Methods Enzymol. 194:21-37.

24. Staub, T. 1991. Fungicide resistance: Practical experience with antiresistance strategies and the role of integrated use. Annu. Rev. Phyto- pathol. 29:421-442.

25. Van Der Vlugt-Bergmanns, C. J. B., Brandwagt, B. F., Van't Klooster, J. W., Wagemakers, C. A. M., and Van Kan, J. A. L. 1993. Genetic variation and segregation of DNA polymorphism in Botrytis cinerea. Mycol. Res. 97:1193-1200. 